DOI: $\underline{10.7242 / 2658-705 X / 2019.3 .8}$

УДК 53.083 .8

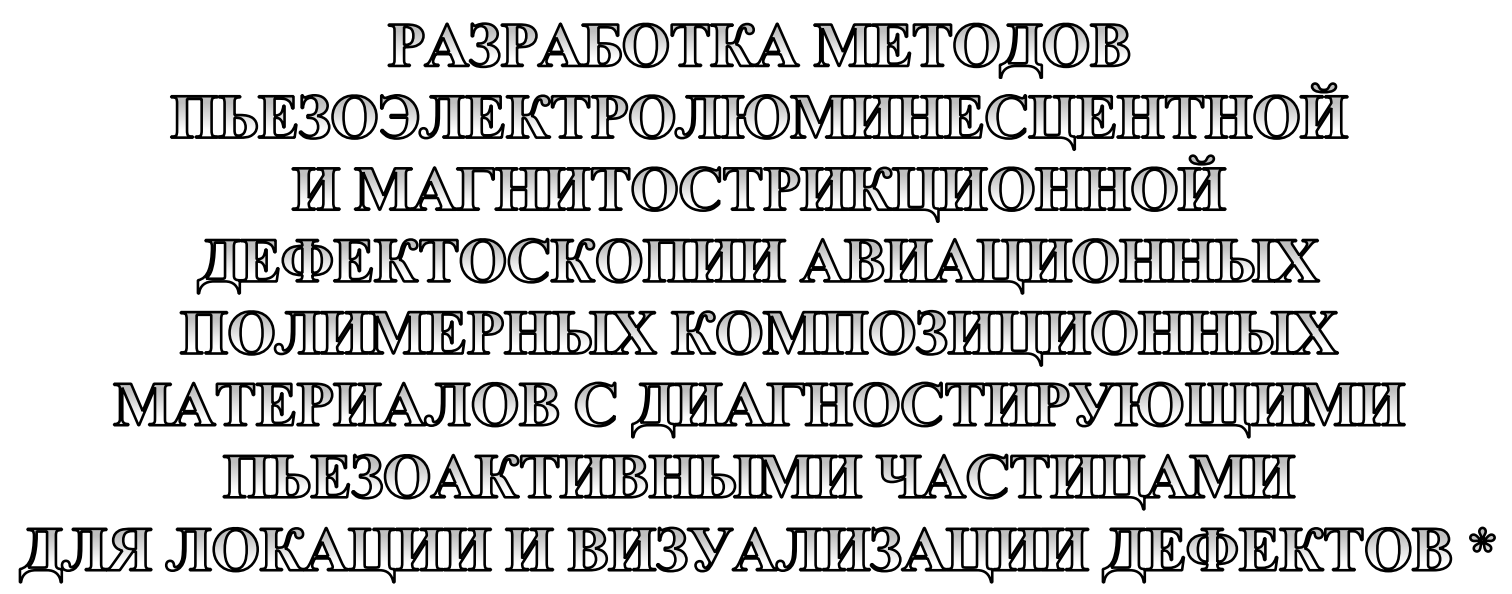

А.А. Паньков, Пермский начиональный исследовательский политехнический университет П.В. Писарев, Пермский национальный исследовательский политехнический университет М.М. Шобей, Пермский национальный исследовательский политехнический университет

В Проекте разработаны новые пьезоэлектролюминесцентные оптоволоконные датчики для интеграции в композитные структуры с целью уточненного диагностирования и мониторинга пространственных распределенных скалярных и тензорных фризико-механических полей, в частности: температуры давления и объемного деформированного состояния внутри нагруженных композитных конструкций по результатам обработки интенсивностей интегральных моно- или полихромных световых сигналов на выходе из оптоволокна датчика.

Разработаны принципиальные схемы функционирования пьезоэлектролюминесцентных оптоволоконных датчиков $и$ новые численные алгоритмы обработки информативных интегральных световых сигналов на выходах из оптоволокон. Информативный световой сигнал появляется как результат «механолюминесцентного эффректа», обусловленного взаимодействием пьезоэлектрического и электролюминесцентного слоев датчика. Далее световые сигналы передаются по оптоволокну к приемнику-анализатору; управляющие электрические сигналы на электродах позволяют находить локации неоднородностей диагностируемых полей по длине датчика.

Представлены результаты численного моделирования «отсканированных» реальных распределений и функций плотностей распределений диагностируемых полей по длине датчиков; здесь функции плотностей распределений найдены как решения интегрального уравнения Фредгольма

\footnotetext{
* Работа выполнена при финансовой поддержке гранта РФФИ № 16-41-590726 «Разработка методов пьезоэлектролюминесцентной и магнитострикционной дефектоскопии авиационных полимерных композиционных материалов с диагностирующими пьезоактивными частицами для локации и визуализации дефектов».
} 
1-го рода с использованием новых алгоритмов обработки информативных интегральных световых сигналов на выходе из оптоволокна.

Ключевые слова: дефектоскопия, смарт-технологии, датчик, механолюминесцентный эффект, пьезорезонатор, оптоволокно, интегральное уравнение Фредгольма, электроупругость, численное моделирование.

\section{Введение}

Сенсорная техника за последние годы развилась в самостоятельную ветвь измерительной техники и к датчикам физико-механических параметров состояния сложных механических и медико-биологических систем предъявляются все более высокие требования, в частности, наряду с высокими метрологическими характеристиками особое значение придается их высокой надежности, долговечности, стабильности, малым габаритам, массе и энергопотреблению, возможности встраивания в объекты и системы мониторинга, совместимости с микроэлектронными и компьютерными устройствами обработки информации, низкой себестоимости, что в наибольшей степени характеризует именно оптико-электронные волоконные датчики. В [1-5] даны классификация, принципы действия, конструкции, параметры и характеристики современных оптико-электронных и волоконно-оптических датчиков, проведен анализ влияния различных факторов на характеристики датчиков и приведены принципиальные схемы построения электронных и оптических датчиков для решения различных промышленных, технологических и медицинских задач. Для мониторинга структурных полей деформирования, диагностирования возникновения и развития технологических и эксплуатационных дефектов в элементах композитных конструкций необходимы современные высокоточные датчики на основе интеллектуальных материалов в качестве чувствительных, трансляционных, управляющих и адаптирующихся к заданным условиям диагностики элементов для интеграции в сложные композитные структуры $[6,7]$.

Цель Проекта - решение фундаментальной задачи обеспечения безопасности эксплуатации и контроля качества авиационных изделий из полимерных композиционных материалов на основе разработки новых методов пьезоэлектролюминесцентной и магнитострикционной дефектоскопии полимерных композиционных материалов с диагностирующими пьезоактивными частицами для диагностики появления, локации и визуализации технологических и эксплутационных дефектов в композитных структурах, получение новых знаний в области создания композиционных материалов нового поколения с внедренными в их структуру оптическими и пьезоактивными элементами для получения возможности диагностики и управления характеристиками материалов в процессе эксплуатации с использованием смарт-технологий. Объектом исследования Проекта являются новые пьезоэлектролюминесцентные оптоволоконные датчики для интеграции в сложные композитные структуры с целью уточненного мониторинга и диагностирования пространственных линейных распределений полей температуры, давления и сложного объемного напряженно-деформированного состояния внутри нагруженных композитных конструкций по результатам обработки интенсивностей интегральных моноили полихромных световых сигналов на выходе из оптоволокна датчика.

По результатам выполнения Проекта сделаны 25 научных публикаций [8-32], в том числе: 12 научных статей [8-19], 5 тезисов докладов конференций [20-24], поданы 8 заявок и получены 7 патентов на изобретения [25-32].

\section{Датчики и принципы функционирования}

Пьезоэлектролюминесцентные оптоволоконные датчики предназначены для 
уточненного диагностирования распределения давления $p$ и/или температуры $T$ (рис., a) [25], осевых усилий $N_{1}, N_{3}$, крутящих $M_{11}, M_{33}$ и изгибных $M_{13}, M_{31}$ моментов в сечениях пластин и оболочек (рис., б) [29] и сложного объемного напряженно-деформированного состояния $\boldsymbol{\sigma}^{*}$ внутри композитных конструкций (рис., в) [26] по результатам обработки приемником-анализатором интенсивностей $I$ интегральных световых сигналов на выходе из оптоволокна датчика. Датчики (см. рис.) представляют собой оптоволокно 1 с коаксиальными электролюминесцентным 2 и пьезоэлектрическим 3 слоями; оптоволокно и электролюминесцентный слой разделены внутренним светопрозрачным или перфорированным управляющим электродом 4, на поверхности пьезоэлектрического слоя расположен внешний управляющий электрод 5 . Буферный слой 6 необходим для механической трансляции на пьезоэлементы датчика лишь однородной макроскопической (усредненной) составляющей микро-

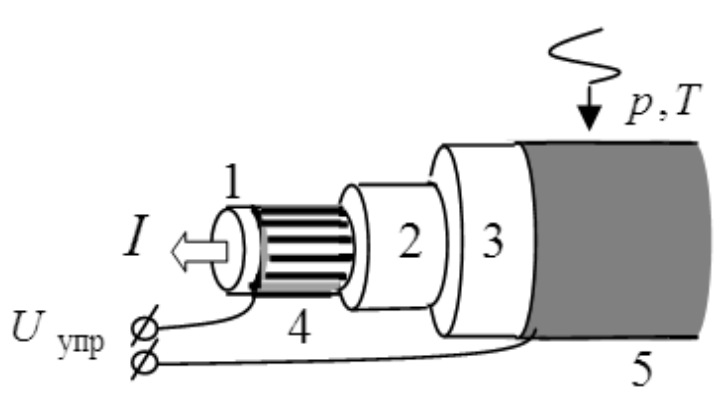

неоднородного напряженно-деформированного состояния из области диагностируемой нагруженной композитной области 7, в частности, пластины (рис., б) или объемной конструкции (рис., в) с целью исключения «паразитного» влияния случайных полей пульсаций микроструктуры в области 7 окрестности датчика на результаты измерения.

Буферный слой 6 может являться элементом внешнего защитного корпуса датчика (см. рис., б) или клеевой прослойкой между корпусом и элементом диагностируемой конструкции. В датчике давления и/или температуры (см. рис., $a$ ) пьезоэлектрический слой имеет радиальную поляризацию и однороден по окружной координате, а в датчиках сложного напряженного состояния электролюминесцентный и пьезоэлектрический слои разделены общими для обоих радиально-продольными границами на геометрически равные, в частности для шестипараметрических датчиков (см. рис., б, в), шесть «измерительных элементов» - цилиндрических двухслойных секторов. В измерительных элементах

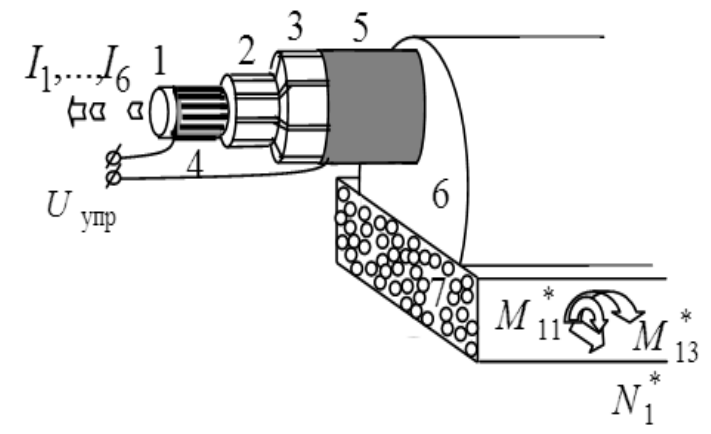

$a$

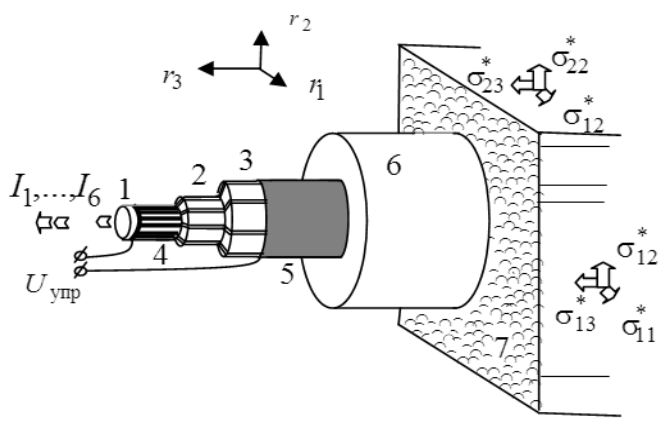

$\sigma$

Рис. Датчик давления и/или температуры (а), поверхностный (б) и встраиваемый (в) датчики сложного напряженного состояния 
датчика (см. рис., б, в) направления пространственных поляризаций пьезоэлектрических фаз (пьезоэлементов) и частоты светоотдач электролюминесцентных фаз различны по всем шести секторам; направления поляризаций пьезоэлементов задаются из условия некомпланарнасти направлений поляризаций для произвольных трех секторов датчика.

Пьезоэлектрические элементы могут представлять собой различные или один и тот же пьезоэлектрик, в частности полимерный трансверсально-изотропный материал PVDF, но с различными пространственными направлениями поляризации по секторам; направление поляризации является осью симметрии пьезоэлектрика PVDF. Информативные световые сигналы возникают на локальных участках измерительных элементов датчика в силу механолюминесцентного эффекта (обусловленного взаимодействием пьезоэлектрического 3 и электролюминесцентного 2 элементов датчика), проникают в оптоволокно 1 через светопрозрачный электрод 4 и передаются по оптоволокну 1 к приемнику-анализатору; управляющее напряжение $U_{\text {упр }}$ на электродах 4,5 позволяет диагностировать локации неоднородностей давления, температурных и деформационных полей в композитных конструкциях с использованием разработанных в Проекте алгоритмов сканирования [8-19].

Датчики (см. рис.) характеризуются своими управляющими $\mathbf{a}_{1}$ и информативными а $\mathbf{a}_{2}$ передаточными коэффициентами, которые устанавливают линейную связь между электрическим напряжением на электролюминесцентном слое $U_{\text {люм }}$ (см. рис., $a$ ) или, для случая шестипараметрических датчиков, на каждом из шести элементах электролюминесцентного

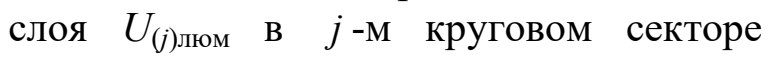
(см. рис., б) со значением приложенного к электродам датчика управляющего электрического напряжения $U_{\text {упр и диагности- }}$ руемыми параметрами в поперечном сечении датчика с координатой $r_{3}, j=\overline{1,6}$. В частности, для датчика давления (см. рис., $a$ ) имеем разложение

$$
U_{\text {люм }}=a_{1} U_{\text {упр }}+a_{2} p,
$$

для поверхностного датчика (см. рис., б)

$$
U_{(j) \text { люм }}=a_{1(j)} U_{\text {упр }}+a_{2(j) m n} \varepsilon_{m n}^{*},
$$

где искомые диагностируемые компоненты обобщенных макродеформаций локального участка композитной пластины $\boldsymbol{\varepsilon}^{*}=\left\{\varepsilon_{11}^{*}, \varepsilon_{33}^{*}, \theta_{11}^{*}, \theta_{22}^{*}, \theta_{12}^{*}, \theta_{21}^{*}\right\}, \quad$ мембранные осевые деформации $\varepsilon_{11}^{*}, \varepsilon_{33}^{*}$, относительные углы закручиваний $\theta_{11}^{*}=\partial \phi_{11} / \partial r_{1}$, $\theta_{33}^{*}=\partial \phi_{33} / \partial r_{3}$ сечений вокруг осей $r_{1}, r_{3}$ и поворотов $\theta_{13}^{*}=\partial \phi_{13} / \partial r_{1}, \theta_{31}^{*}=\partial \phi_{31} / \partial r_{3}$ ceчений вокруг осей $r_{3}, r_{1}$ при изгибах в плоскостях $r_{1} r_{2}, r_{2} r_{3}$, функции углов поворотов $\phi_{i j}$ сечений пластины с нормалями $r_{i}$ вокруг осей $r_{j}$, число измерительных элементов $n=6$, индексы $i, j=1,3$; для датчика (см рис., в) диагностирования сложного объемного деформированного состояния внутри композитной конструкции имеем $\boldsymbol{\varepsilon}^{*}=\left\{\varepsilon_{11}^{*}, \varepsilon_{22}^{*}, \varepsilon_{33}^{*}, \gamma_{23}^{*}, \gamma_{13}^{*}, \gamma_{12}^{*}\right\}$ с искомыми осевыми $\varepsilon_{11}^{*}, \varepsilon_{22}^{*}, \varepsilon_{33}^{*}$ и сдвиговыми $\gamma_{23}^{*}, \gamma_{13}^{*}, \gamma_{12}^{*}$ деформациями в разложении (2).

Датчики (см рис.) работают следующим образом. Действие диагностируемых деформационных параметров $\boldsymbol{\varepsilon}^{*}$ в локальной области композитной конструкции приводит к деформациям пьезоэлектрических элементов, в общем, многопараметрического датчика (см. рис., б, в) и возникновению внутри них соответствующих электрических полей. В объеме датчика пьезоэлектрические поля, обусловленные действием $\boldsymbol{\varepsilon}^{*}$, суммируются с электрическим полем от управляющего напряжения $U_{\text {упр }}$ на электродах датчика и результирующее электрическое поле с напряжением $U_{\text {люм }}(1)$ или $U_{(j) \text { люм }}(2)$ действует на электролюминесцентные элементы датчика, вызывая их свечение, при этом для случая (2) (см. рис., б, в) на различных по элементам частотам.

Далее световой полихромный поток от 
Далее световой полихромный поток от свечений электролюминесцентных элементов проникает (через фотопрозрачный внутренний электрод) вовнутрь оптоволокна и передается к приемнику-анализатору на выходе из оптоволокна. Анализ зависимостей интегральных интенсивностей световых потоков, в частности, $I_{1}, \ldots, I_{6}$ шести различных частот на выходе из оптоволокна от управляющего напряжения $U_{\text {упр по- }}$ зволяет сделать вывод о величине и локациях неоднородностей обобщенного деформированного состояния $\boldsymbol{\varepsilon}^{*}$ по длине датчика. Например, искомые компоненты $\boldsymbol{\varepsilon}^{*}$ в локальной области композитной конструкции (см. рис.,в) определяем из решения системы линейных алгебраических уравнений $a_{2(j) m n} \varepsilon_{m n}^{*}=\Delta_{j}$ через найденные приемником-анализатором численные значения электрических напряжений $\Delta_{j} \equiv U_{(j) \text { люм }}-a_{1(j)} U_{\text {упр }}$ на электролюминесцентных элементах в $j$-х секторах $(j=\overline{1,6})$ по алгоритмам $[9,10,13]$ с учетом нелинейных зависимостей интенсивностей исходящих из электролюминесцентных элементов световых потоков от величин действующих на них электрических напряжений.

\section{Алгоритмы диагностирования}

Датчики (см. рис.) позволяют находить как интегральные характеристики диагностируемых полей, например, осредненные значения или функции плотностей распределений диагностируемых параметров $[11,16-18]$, так и сканировать реальное распределение параметров по длине датчика $[9,10,13]$.

Функции плотностей распределений диагностируемых параметров, например, температуры $f_{T}(\tau)$ [16-18] и/или давления $f_{p}(\tau)$ [11] по длине датчика, могут быть найдены из решения интегрального уравнения Фредгольма 1-го рода

$$
g(x)=\int_{-\infty}^{\infty} K(x-s) f(s) \mathrm{d} s,
$$

при этом для случая нахождения функции $f(s)=f_{T}(\tau)_{\mid \tau=s / k_{v}}$ по результатам измерений в «резонансном режиме» значений производной $g(v)=\mathrm{d} \tilde{I} / \mathrm{d} v$ амплитуды интенсивности свечения $\tilde{I}$ на выходе из оптоволокна по частоте $v$ задаваемого переменного электрического напряжения на электродах датчика имеем обозначения параметров $x=v, \quad s=k_{v} \tau$ и ядра Фредгольма, которое рассчитывается $K(v)=\frac{l}{k_{v}}\left(\frac{\partial^{2} \tilde{I}_{0}(v, \bar{l})}{\partial v \partial \bar{l}}\right)_{\mid \bar{l}=0}$ через считающуюся известной амплитудно-частотную характеристику $\tilde{I}_{0}(v, \bar{l})$ фрагмента датчика длиной $\bar{l}$, длина датчика $l$, коэффициент пропорциональности $k_{v}$ для рассматриваемого рабочего температурного диапазона датчика с учетом, что изменение резонансной частоты $\Delta_{T} \equiv v_{T}-v_{0} \approx k_{v} \Delta T$ пропорционально изменению температуры $\Delta T$ локального участка датчика.

Для случая нахождения функции $f(s)=\left.f_{p}(\tau)\right|_{\tau=-s / a_{2}}$ по результатам измеряемых значений производной

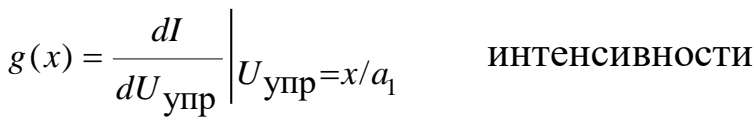
свечения $I$ на выходе из оптоволокна по величине постоянного электрического

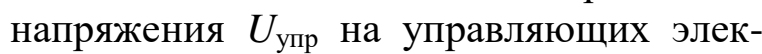
тродах датчика имеем обозначения параметров $X_{=} a_{1} U_{\text {упр }}, S_{=}-a_{2} \zeta$ и ядра Фредгольма $K(\bar{U})=\frac{a_{1}}{a_{2}} \frac{\mathrm{d} \bar{I}(\bar{U})}{\mathrm{d} \bar{U}}$, которое рассчитывается через считающуюся известной «S-образную» функцию свечения $\bar{I}(\bar{U})$ электролюминесцентного слоя от действия на него электрического напряжения $\bar{U}$, передаточные коэффициенты $a_{1,2}(1)$.

Для случая сканирования реального распределения диагностируемых параметров, например давления $p\left(r_{3}\right)$ по продольной координате $r_{3}$ датчика (см. рис., $a$ ) могут быть использованы бегущие вдоль 
электродов видеоимпульс [13] или гармоническая волна управляющего электрического напряжения $[9,10]$, когда каждое малое приращение $\Delta \mathrm{U}_{a}$ амплитуды волны $\mathrm{U}_{a(i)}=\mathrm{U}_{a(i-1)}+\Delta \mathrm{U}_{a}$ при переходе от (i-1)-го к последующему $i$-му шагу сканирования инициирует свечение (дополнительно к уже светящимся участкам) новых участков электролюминесцентного слоя датчика на участках действия значения давления $p$ из интервала $p_{(i+1)} \prec p \prec p_{(i)}$, где $p_{(i+1)}=p_{(i)}-\Delta U_{a} a_{1} / a_{2}$, пороговое значение амплитуды $U_{a(0)}$ начала свечения на выходе из оптоволокна датчика, координата $r_{3} \in(0 ; l)$, длина датчика $l$, индекс $i=\overline{1, n}$. На $i$-м шаге сканирования в момент времени $t$ интенсивность света на выходе из оптоволокна

$$
I_{i}(t)=\sum_{i^{\prime}=1}^{i} I_{i^{\prime}(i)}(t)
$$

складывается из интенсивностей свечений $I_{i^{\prime}(i)}(t)$ соответствующих координатных участков $\mathbf{z}_{(i)}$ с давлением $p_{(i)} \geq p_{(i)}$ для случая ${ }_{i \geq i}$. В результате для случая $i \geq 2$ «последняя» или $i$-я составляющая

$$
\Delta I_{i}(t) \equiv I_{i(i)}(t)=I_{i}(t)-\sum_{i^{\prime}=1}^{i-1} I_{i^{\prime}(i)}(t)
$$

в суммарной $\mathrm{I}_{i}(t)$ интенсивности свечения на выходе из оптоволокна (4) позволяет определить локацию участков $\mathbf{z}_{(i)}$ с давлениями $\mathrm{p}_{(i)}$; для случая $i=1$ имеем $\Delta I_{1}(t)=I_{1}(t)$. «Вычеты» $I_{i^{\prime}(i)}(t)$ в (5) рассчитываются для случая $i \geq 2$ с использованием заданной функции свечения электролюминесцентного слоя и найденных на предыдущих шагах сканирования локаций участков $\mathbf{z}_{\left(i^{\prime}\right)}$ с давлениями $p_{(i)}, i^{\prime}=\overline{1, i-1}$.

Результирующие функции импульсов свечения $\Delta I_{i}(t)(5)$ носят экспериментально-расчетный характер, так как на каждом шаге ${ }_{i}$ функции $I_{i}(t)$ определяется экспериментально, а $I_{i^{\prime}(i)}(t)$ рассчитываются по найденным на предыдущих шагах $i^{\prime}$ сканирования значениям $p_{(i)}, \mathbf{z}_{(i)}$. На каждом $i$-м шаге сканирования на графике функции $\Delta I_{i}(t)$ (5) находим моменты времени для начала и окончания каждого импульса свечения функции $\Delta I_{i}(t)$, по которым рассчитываем искомые локации участков $\mathbf{z}_{(i)}$ с давлениями $P_{(i)}$. Рассмотренный алгоритм сканирования бегущей волной может быть применен как для однопараметрических (см. рис., $a$ ), так и многопараметрических (см. рис., б, в) датчиков.

\section{Заключение}

Разработанные в Проекте пьезоэлектролюминесцентные оптоволоконные датчики (см. рис.) для диагностирования протяженных неоднородных полей температуры, давления, сложного объемного напряженного состояния внутри композитных сред и новые алгоритмы функционирования и обработки информативных интегральных оптических сигналов на выходе из оптоволокон датчиков [832] найдут применение в гидро- и аэродинамике, медико-биологических исследованиях, мониторинге протяженных строительных конструкций: плотин, мостов, нефте- и газопроводов и в аэрокосмической технике для дефектоскопии и мониторинга сложного напряженного состояния внутри композитных конструкций, в частности, актуальным является практическое использование этих датчиков в новом российском самолете МС-21 и двигателе ПД-14 (ОАО «Авиадвигатель», г. Пермь) с целью локации и визуализации дефектов типа расслоений, непроклеев, пор в композиционных полимерных материалах, высокочувствительных к таким дефектам, для повышения надежности и несущей способности композитных фланцев корпусных деталей авиадвигателей. Предложенные в Проекте оптоволоконные датчики могут быть изготовлены в Пермской научно-производственной приборостроительной компании, что позволит создать новые рабочие места, снизить вес, повысить надежность, конкурентноспособность, экологические 


\begin{tabular}{llllll}
\hline параметры и экономичность авиацион- & ных конструкций и объектов нефте- \\
ных & двигателей, & строитель- газового комплекса Пермского края.
\end{tabular}

Библиографический список

1. Fraden J. Handbook of Modern Sensors. - Springer-Verlag New York, 2004. - 589 p.

2. Next Generation Sensors and Systems / Ed.: Mukhopadhyay, Subhas Chandra (Ed.). - Springer International Publishing, 2016. - $330 \mathrm{p}$.

3. Fiber Optic Sensors / Ignacio R. Matias, Satoshi Ikezawa, Jesus Corres, Springer International Publishing, 2017. - $381 \mathrm{p}$.

4. Sensors and Microsystems / Editors: Leone A., Forleo A., Francioso L., Capone S., Siciliano P., Di Natale C. Proceedings of the 19th AISEM 2017 National Conference, Springer International Publishing, 2018. - 330 p.

5. Smart Sensors and MEMS / Editors: S. Nihtianov, A. Luque, Woodhead Publishing, 2018. - 604 p.

6. Каблов Е.Н., Сиваков Д.В., Гуляев И.Н., Сорокин К.В., Федотов М.Ю., Дианов Е.М., Васильев C.A., Медведков О.И. Применение оптического волокна в качестве датчиков деформации в полимерных композиционных материалах // Все материалы. Энциклопедический справочник. 2010. -№ 3. - C. 10-15.

7. Шардаков И.Н., Созонов Н.С., Цветков Р.В. Экспериментально-теоретические основы автоматизированных систем деформационного мониторинга с использованием волоконнооптических элементов // Вестник Пермского научного центра. - 2016. - № 4. - C. 91-95.

8. Pan'kov A.A. Mathematical model for diagnosing strains by an optical fiber sensor with a distributed Bragg grating according to the solution of a Fredholm integral equation // Mechanics of Composite Materials. 2018. - № 4. - P. 513-522.

9. Паньков A.A. Пьезоэлектролюминесцентный оптоволоконный датчик для диагностики напряженного состояния и дефектоскопии композитов // Механика композитных материалов. 2017. - T. 53. - № 2. - C. 325-344.

10. Pan'kov A.A. Piezoelectroluminescent optical fiber sensor for diagnostics of the stress state and defectoscopy of composites // Mechanics of Composite Materials. - 2017. - Vol. 53. - № 2. - P. 229-242 (Web of Science).

11. Паньков A.A. Математическое моделирование пьезоэлектролюминесцентного эффекта и диагностика распределения давления по длине оптоволоконного датчика // Вестник ПНИПУ. Механика. - 2016. - №4. - С. 259-272 (Scopus).

12. Паньков A.A. Максвелл-вагнеровская релаксация электрических полей в пьезоэлектролюминесцентном оптоволоконном датчике вибродавления // Журнал радиоэлектроники: электронный журнал. - 2017. - № 11; http://jre.cplire.ru/jre/nov17/6/text.pdf

13. Паньков A.A. Математическая модель импульсного сканирования давления по длине пьезоэлектролюминесцентного оптоволоконного датчика // Вестник ПНИПУ. Механика. - 2018. № 1. - C. 73-82 (Scopus).

14. Паньков A.A. Пьезоэлектролюминесцентный оптоволоконный датчик для диагностики объемного напряженного состояния в композитных конструкциях // Механика композитных материалов. 2018. - T. 54. - № 2. - C. 233-248.

15. Pan'kov A.A. A piezoelectroluminescent fiber-optical sensor for diagnostics of the 3D stress state in composite structures // Mechanics of Composite Materials. - 2018. - Vol. 54. - № 2. - P. 155-164 (Web of Science).

16. Паньков A.A. Резонансная диагностика распределения температуры пьезоэлектролюминесцентным оптоволоконным датчиком по решению интегрального уравнения Фредгольма // Вестник ПНИПУ. Механика. - 2018. - № 2. - С. 72-82 (Scopus).

17. Паньков A.A. Резонансный пьезоэлектролюминесцентный оптоволоконный датчик температурного поля в композитных конструкциях // Механика композитных материалов. - 2019. - Vol. 55. - № 3. - P. 1-16.

18. Pan'kov A.A. Resonant piezoelectroluminescent fibre-optical sensor of the temperature field in composite designs // Mechanics of Composite Materials. - 2019. - Vol. 55. - № 3. - P. 1-16 (Web of Science).

19. Pan'kov A.A. Piezoelectroluminescent fiber-optic sensors for temperature and deformation fields // Sensors and Actuators A: Physical. - 2019. - Vol. 288. - P. 171-176 (Web of Science).

20. Паньков A.A. Пьезоэлектролюминесцентный оптоволоконный датчик диагностирования деформационных полей в композитных конструкциях / Тез. докладов VII Всерос. науч. конф. с междунар. участием «Механика композиционных материалов и конструкций, сложных и гетерогенных сред». - М:, 2017. - С. 143-145.

21. Паньков А.А., Шобей М.М. Оптоволоконные датчики диагностирования композитных конструкций / Тез. докладов XVIII Всерос. науч.-технич. конф. «Аэрокосмическая техника, высокие технологии и инновации», - Пермь, 2017. - С. 201-204.

22. Паньков А.А., Писарев П.В. Численный расчет в ANSYS информативных и управляющих передаточных коэффициентов пьезоэлектролюминесцентного оптоволоконного датчика / Тез. 
докладов XVIII Всерос. науч.-технич. конф. «Аэрокосмическая техника, высокие технологии и инновации». - Пермь, 2017. - С. 198-201.

23. Паньков A.A., Писарев П.В. Численная модель в ANSYS поверхностного пьезоэлектролюминесцентного оптоволоконного датчика мембранных и моментных деформаций пластин / Тез. докладов Всерос. науч.-технич. конф. «Аэрокосмическая техника, высокие технологии и инновации». - Пермь, 2018. - С. 393-395.

24. Паньков А.А., Шобей М.M. Численная модель осесимметричной стационарной задачи электроупругости пьезоэлектролюминесцентного оптоволоконного датчика вибродавления / Тез. докладов Всерос. науч.-технич. конф. «Аэрокосмическая техника, высокие технологии и инновации», - Пермь, 2018. - С. 395-397.

25. Паньков А.А. Патент РФ № 2630537 от 11.09.2017.

26. Паньков А.А. Патент РФ № 2643692 от 05.02.2018.

27. Паньков А.А. Патент РФ № 2664684 от 21.08.2018.

28. Паньков А.А, Аношкин А.Н. Патент РФ № 2670220 от 19.10.2018.

29. Паньков А.А. Патент РФ № 2684001 от 03.04.2019.

30. Паньков А.А. Патент РФ № 2690416 от 03.06 .2019$.

31. Паньков А.А. Патент РФ № 2690732 от 05.06.2019.

32. Паньков А.А. Заявка на изобретение РФ № 2018145674 от 21.12.2018 г.

\title{
DEVELOPMENT OF PIEZOELECTROLUMINESCENT AND MAGNETOSTRICTION DETECTOSCOPY METHODS OF AVIATION POLYMER COMPOSITION MATERIALS WITH DIAGNOSTIC PIEZOACTIVE PARTICLES FOR LOCATION AND OF DEFECTS VISUALIZATION
}

\author{
A.A. Pankov, P.V. Pisarev, M.M. Shobey \\ Perm National Research Polytechnic University
}

The new piezoelectroluminescent optical fiber sensors are developed for integration into composite structures for the purpose of specified diagnosing and monitoring spatial distributed scalar and tensor physical and mechanical fields, in particular, the temperature, pressure and volumetric deformed state in the loaded composite designs by processing results of intensities for integrated mono or multi-colour light signals at the exit of the sensor fiber. New schemes of the functioning and numerical processing algorithms of informative integrated light signals at the exit of optical fiber sensors were developed. The informative light signal appears as a result of «mechanoluminescent effect» by interaction of piezoelectric and electroluminescent of the sensor layers. Light signals are transmitted via optical fiber to a «receiver analyzer»; control electric signals on the electrodes allow to find locations of heterogeneities of diagnosed fields along the length of the sensor. Results of numerical modeling the «scanned» real distributions and its density functions of the diagnosed fields along the length of sensors are presented; density functions are solutions of the Fredholm integral equation of the 1st kind with the use of the new developed processing algorithms of informative integrated light signals at the exit of the optical fiber.

Keywords: defectoscopy, smart technologies, sensor, mechanoluminescent effect, piezoelectric resonator, optical fiber, integrated equation of Fredholm, electroelasticity, numerical modeling.

\section{Сведения об авторах}

Паньков Андрей Анатольевич, доктор физико-математических наук, доцент, профессор кафедры механики композиционных материалов и конструкций, Пермский национальный исследовательский политехнический университет (ПНИПУ), 614990, г. Пермь, Комсомольский пр., 29; e-mail: a_a_pankov@mail.ru

Писарев Паел Викторович, кандидат технических наук, доцент кафедры механики композиционных материалов и конструкций ПНИПУ; e-mail: pisarev@pstu.ru

Шобей Максим Михайлович, заведующий лабораториями кафедры механики композиционных материалов и конструкций ПНИПУ; e-mail: maksim-shobey@yandex.ru 